\title{
A PERFORMANCE MODELING AND DECISION SUPPORT SYSTEM FOR A FEED WATER UNIT OF A THERMAL POWER PLANT
}

\author{
S. Gupta ${ }^{1}$, P.C. Tewari ${ }^{2}$ and A.K. Sharma ${ }^{3}$ \\ ${ }^{1}$ Department of Mechanical Engineering \\ HCTM, Kaithal (Haryana), India \\ sorabh_gupta123@rediffmail.com \\ ${ }^{2}$ Department of Mechanical Engineering \\ NIT, Kurukshetra (Haryana), India \\ pctewari1@rediffmail.com \\ ${ }^{3}$ Department of Mechanical Engineering \\ CRSCE, Murthal, Sonipat (Haryana), India
}

\begin{abstract}
The present paper discusses the performance modeling and decision support system for a feed water unit of a thermal power plant using the concept of performance analysis and modeling. A feed water unit ensures a proper supply of water for the sound functioning of a thermal power plant. The decision support system for a feed water unit has been developed with the help of performance modeling using a probabilistic approach. After drawing a transition diagram, differential equations are generated. After that, steady state probabilities are determined. Some decision matrices are also developed, which provide various performance levels for different combinations of failure and repair rates of all subsystems. Based upon various availability values obtained in decision matrices and plots of failure rates / repair rates of various subsystems, the performance of each subsystem is analyzed, and maintenance decisions are made for all subsystems.
\end{abstract}

\section{OPSOMMING}

Vertoningsanalise en -modellering word gedoen vir die toevoerwatersisteem van ' $\mathrm{n}$ termiese kragstasie. Toevoerwater is ' $n$ belangrike factor vir die doeltreffende bedryf van ' $n$ kragstasie. Die vertoningsanalise en -model is probalisties van aard. ' $n$ Toestandoorgangsdiagram en bypassende differensiaalvergelykings word gebruik, gevolg deur bepaling van die bestandige sisteemtoestand. Bykomende aandag word gegee aan relevante subsisteme. Die vertoning van subsisteme word gebasseer op verskeie beskikbaarheidswaardes om sodoende instandhouding to optimiseer. 


\section{NOTATIONS}

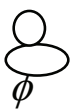

$\lambda$

B, C, F

$b, c, f$

$\phi_{1}, \phi_{2}, \phi_{3}$

$\lambda_{1}, \lambda_{2}, \lambda_{3}$
Indicates the system is in a working state. Indicates the system is in a failed state.

Failure rate

Repair rate

Represent full working states of the boiler, condenser, and feed pump respectively.

Represent failed states of the boiler, condenser, and feed pump respectively.

Mean constant failure rates of $B, C, F$ respectively.

Mean constant repair rates of $b, c, f$ respectively.

\section{ASSUMPTIONS}

(1) The performance of a repaired unit is as good as new, for a specified duration.

(2) Failure and repair rates are constant and statistically independent.

(3) The standby unit (F) is of the same nature and capacity as the original unit.

(4) There are no simultaneous failures among the subsystems.

\section{INTRODUCTION}

Reliability analysis is one of the main tools to ensure agreed delivery deadlines, which in turn maintain certain intangible factors such as customer goodwill and company reputation [1]. Downtime often leads to both tangible and intangible losses. These losses may be due to some unreliable subsystems/components; so an effective strategy needs to be framed for the maintenance, replacement, and design changes related to those subsystems and components [2-5]. A measure of how well a system performs or meets its design objectives is provided by the concept of system reliability. In most of the complex systems encountered in practice, it has been observed that they consist of components and subsystems connected in series, parallel, or standby, or a combination of these. A thermal power plant is a complex engineering system comprised of various units: coal handling, steam generation, cooling water, crushing, ash handling, power generation, and feed water [6].

For regular and economical generation of steam, it is necessary to maintain each subsystem of the feed water unit. The failure of each item of equipment or subsystem depends upon the operating conditions and maintenance policies used [6]. From economic and operational points of view, it is desirable to ensure an optimum level of system availability. The goal of maximum steam generation may be achieved under the given operational conditions, making the feed water unit failure-free, by examining the behaviour of the system and making a top priority maintenance decision for the most critical subsystems. The maintenance aspects of a feed water unit - an important functional part of the steam generation unit of a thermal power plant - has been discussed [7]. 


\section{FEED WATER UNIT DESCRIPTION}

The feed water unit consists of three subsystems:

(1) Boiler (B): This subsystem is without any standby unit, so its failure leads to a system failure.

(2) Condenser (C): This subsystem consists of a single condenser.

(3) Feed Water Pump (F): This subsystem consists of two pumps; one works while the other remains on standby. System failure occurs only when both units fail simultaneously.

The transition diagram of the feed water unit is given in Figure 1, in which states 0 and 3 are working at full capacity and states 1,,2, 4, 5, and 6 have failed.

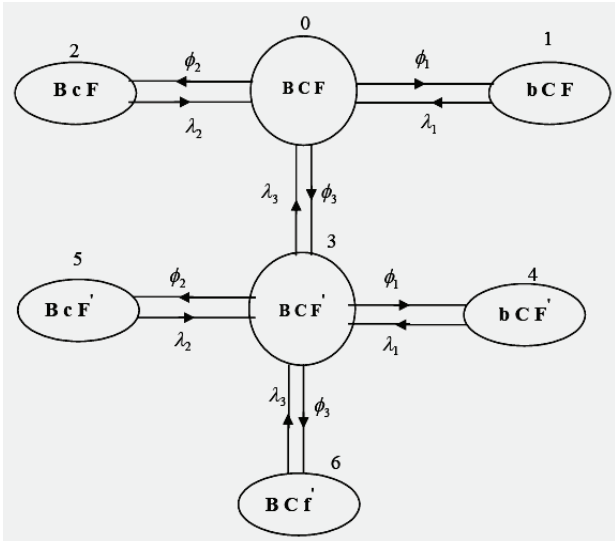

Figure 1: T ransition diagram of a feed water unit

\section{PERFORMANCE MODELING OF FEED WATER UNIT}

Traditional binary reliability models allow only two functional states for a system and for each of its components: perfect functionality (UP) and complete failure (DOWN). Multi-state system (MSS) reliability analysis relates to systems for which one cannot formulate an 'all or nothing' failure criterion [8-9].

The mathematical modeling is done using probabilistic considerations and differential equations, using the Markov birth-death process. These equations are solved to determine the steady state availability of the feed water unit. Various probability considerations give the following differential equations associated with the feed water unit [10-11]. 


$$
\begin{aligned}
& P_{o}(t)\left[\frac{d}{d t}+\phi_{1}+\phi_{2}+\phi_{3}\right]=P_{1}(t) \cdot \lambda_{1}+P_{2}(t) \cdot \lambda_{2}+P_{3}(t) \cdot \lambda_{3} \\
& P_{3}(t)\left[\frac{d}{d t}+\phi_{1}+\phi_{2}+\phi_{3}+\lambda_{3}\right] \\
& =P_{4}(t) \cdot \lambda_{1}+P_{5}(t) \cdot \lambda_{2}+P_{6}(t) \cdot \lambda_{3}+P_{0}(t) \cdot \phi_{3} \\
& P_{1}(t)\left[\frac{d}{d t}+\lambda_{1}\right]=P_{0}(t) \phi_{1} \\
& P_{2}(t)\left[\frac{d}{d t}+\lambda_{2}\right]=P_{0}(t) \cdot \phi_{2} \\
& P_{4}(t)\left[\frac{d}{d t}+\lambda_{1}\right]=P_{3}(t) \cdot \phi_{1} \\
& P_{5}(t)\left[\frac{d}{d t}+\lambda_{2}\right]=P_{3}(t) \cdot \phi_{2} \\
& P_{6}(t)\left[\frac{d}{d t}+\lambda_{3}\right]=P_{3}(t) \cdot \phi_{3}
\end{aligned}
$$

Using the steady state equation, and by setting $t \rightarrow \infty, \frac{d}{d t} \rightarrow 0$, the above equations reduce to:

$$
\begin{aligned}
& P_{0}\left[\phi_{1}+\phi_{2}+\phi_{3}\right]=P_{1} \lambda_{1}+P_{2} \lambda_{2}+P_{3} \lambda_{3} \\
& P_{3}\left[\phi_{1}+\phi_{2}+\phi_{3}+\lambda_{3}\right]=\lambda_{1} P_{4}+\lambda_{2} P_{5}+\lambda_{3} P_{6}+\phi_{3} P_{0} \\
& P_{1} \lambda_{1}=P_{0} \phi_{1} \\
& P_{2} \lambda_{2}=P_{0} \phi_{2} \\
& P_{4} \lambda_{1}=P_{3} \phi_{1} \\
& P_{5} \lambda_{2}=P_{3} \phi_{2}
\end{aligned}
$$


$P_{6} \lambda_{3}=P_{3} \phi_{3}$

Solving these equations recursively gives:

$$
P_{1}=\frac{\phi_{1}}{\lambda_{1}} P_{0}, P_{2}=\frac{\phi_{2}}{\lambda_{2}} P_{0}, P_{3}=\frac{\phi_{3}}{\lambda_{3}} P_{0}
$$

and using the normalizing condition - i.e., the sum of all state probabilities $=1$ :

i.e. $\sum_{i=0}^{i=6} P_{i}=1$

$$
\therefore P_{0}=\frac{1}{1+\left(1+\frac{\phi_{3}}{\lambda_{3}}\right)\left(\frac{\phi_{1}}{\lambda_{1}}+\frac{\phi_{2}}{\lambda_{2}}+\frac{\phi_{3}}{\lambda_{3}}\right)}
$$

$\therefore$ the availability of system $\left(A_{0}\right)$ is given by the summation of probabilities of all working states - i.e.

$\mathrm{A}_{0}=\mathrm{P}_{0}+\mathrm{P}_{3}$

$$
\begin{aligned}
& \text { or } A_{0}=\left(1+\frac{\phi_{3}}{\lambda_{3}}\right) P_{0} \\
& \therefore A_{0}=\frac{\left(1+\frac{\phi_{3}}{\lambda_{3}}\right)}{1+\left(1+\frac{\phi_{3}}{\lambda_{3}}\right)\left(\frac{\phi_{1}}{\lambda_{1}}+\frac{\phi_{2}}{\lambda_{2}}+\frac{\phi_{3}}{\lambda_{3}}\right)}
\end{aligned}
$$

\section{DECISION SUPPORT SYSTEM}

In the studies of reliability optimization, the number of components is usually taken as a decision variable [12-13]. From the maintenance history sheet of the feed water unit of a thermal power plant, and from discussions with the plant personnel, appropriate failure and repair rates of all three subsystems are taken and decision matrices (availability values) are prepared by putting these failure and repair rates values in expression (8) for $A_{0}$. The decision support system deals with the quantitative analysis of all the factors - the courses of action and states of nature which influence the maintenance decisions associated with the feed water unit of the thermal power plant. These decision models are developed in a real decision- 
making environment - i.e. decision-making under risk (probabilistic model) - and are used to implement the proper maintenance decisions for the feed water unit.

Tables 1, 2, and 3 represent the decision matrices for various subsystems of the feed water unit. These matrices reveal the various availability levels for different combinations of failure and repair rates/priorities. These availability values, obtained in decision matrices for all three subsystems, are plotted. Figures 2, 3, and 4 represent the plots for various subsystems of the feed water unit, depicting the effect of the failure/repair rate of various subsystems on feed water unit availability. On the basis of the decision support system developed, one may select the best possible combinations $(\phi, \lambda)$.

\section{RESULTS AND DISCUSSION}

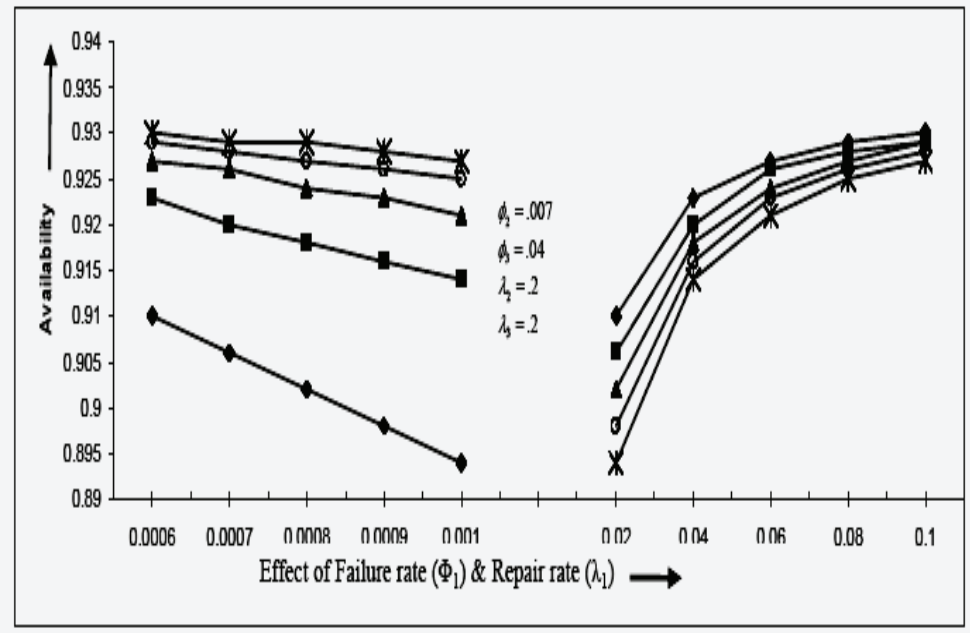

Figure 2: The effect of the failure and repair rate of the boiler subsystem on the feed water unit availability.

Table 1 and Figure 2 reveal the effect of the failure and repair rates of the boiler subsystem on the availability of the feed water unit. It is observed that for some known values of failure / repair rates of condenser and feed water pump $\left(\phi_{2}=\right.$ $0.007, \phi_{3}=0.04, \lambda_{2}=0.2, \lambda_{3}=0.2$ ), as the failure rate of the boiler increases from 0.0006 (once in $1,667 \mathrm{hrs}$ ) to 0.001 (once in $1,000 \mathrm{hrs}$ ), the unit availability decreases by only $1 \%$. Similarly, as the repair rate of the boiler increases from 0.02 (once in $50 \mathrm{hrs}$ ) to 0.1 (once in $10 \mathrm{hrs}$ ), the unit availability increases by approximately $2 \%$. 


\begin{tabular}{ccccccc}
$\lambda_{1}$ & \multicolumn{7}{c}{ Availability $(\mathrm{Av}) \rightarrow \mathrm{A}_{0}$} \\
$\phi_{1}$ & .02 & .04 & .06 & .08 & .1 & $\begin{array}{c}\text { Constant } \\
\text { values }\end{array}$ \\
.0006 & .910 & .923 & .927 & .929 & .930 & $\phi_{2}=.007$ \\
.0007 & .906 & .920 & .926 & .928 & .929 & $\phi_{3}=.04$ \\
.0008 & .902 & .918 & .924 & .927 & .929 & $\lambda_{2}=.2$ \\
.0009 & .898 & .916 & .923 & .926 & .928 & $\lambda_{3}=.2$ \\
.001 & .894 & .914 & .921 & .925 & .927 &
\end{tabular}

Table 1: Decision matrix of the boiler subsystem of the feed water unit

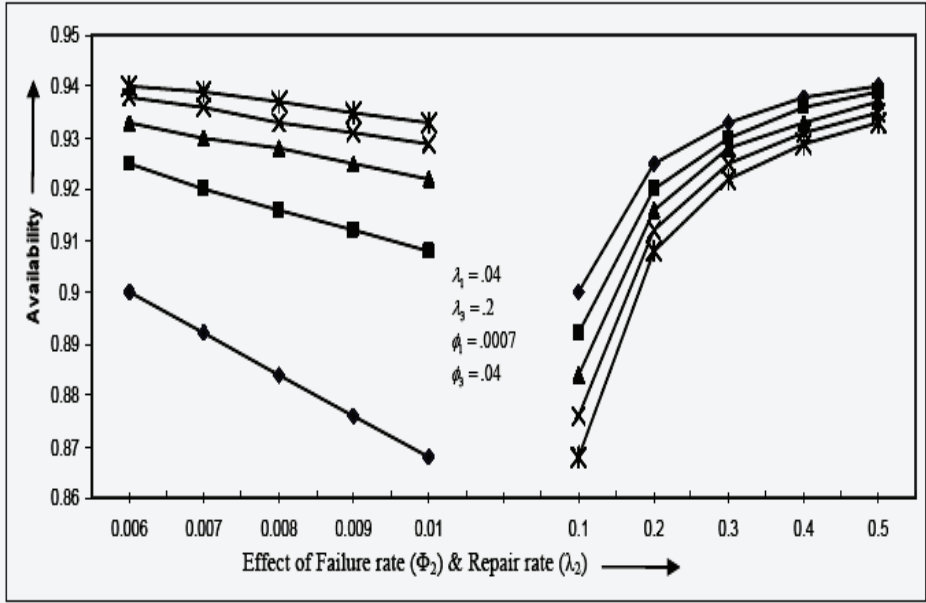

Figure 3: The effect of the failure and repair rate of the condenser subsystem on the feed water unit availability. 


\begin{tabular}{ccccccc}
$\lambda_{2}$ & \multicolumn{7}{c}{ Availibility $(\mathrm{Av}) \rightarrow \mathrm{A}_{0}$} \\
$\phi_{2}$ & .1 & .2 & .3 & .4 & .5 & $\begin{array}{c}\text { Constant } \\
\text { values }\end{array}$ \\
.006 & .900 & .925 & .933 & .938 & .940 & $\lambda_{1}=.04$ \\
.007 & .892 & .920 & .930 & .936 & .939 & $\lambda_{3}=.2$ \\
.008 & .884 & .916 & .928 & .933 & .937 & $\phi_{1}=.0007$ \\
.009 & .876 & .912 & .925 & .931 & .935 & $\phi_{3}=.04$ \\
.01 & .868 & .908 & .922 & .929 & .933 &
\end{tabular}

Table 2: Decision matrix of the condenser subsystem of the feed water unit

Table 2 and Figure 3 highlight the effect of the failure and repair rates of the condenser subsystem on the availability of the feed water unit. It is observed that for some known values of failure / repair rates of boiler and feed water pump $\left(\phi_{1}\right.$. $0.007, \phi_{3}=0.04, \lambda_{1}=0.04, \lambda_{3}=0.2$ ), as the failure rate of the condenser increases from 0.006 (once in $167 \mathrm{hrs}$ ) to 0.010 (once in $100 \mathrm{hrs}$ ), the unit availability decreases by approximately $3 \%$. Similarly, as the repair rate of the condenser increases from 0.10 (once in $10 \mathrm{hrs}$ ) to 0.50 (once in $2 \mathrm{hrs}$ ), the unit availability increases by approximately $4 \%$.

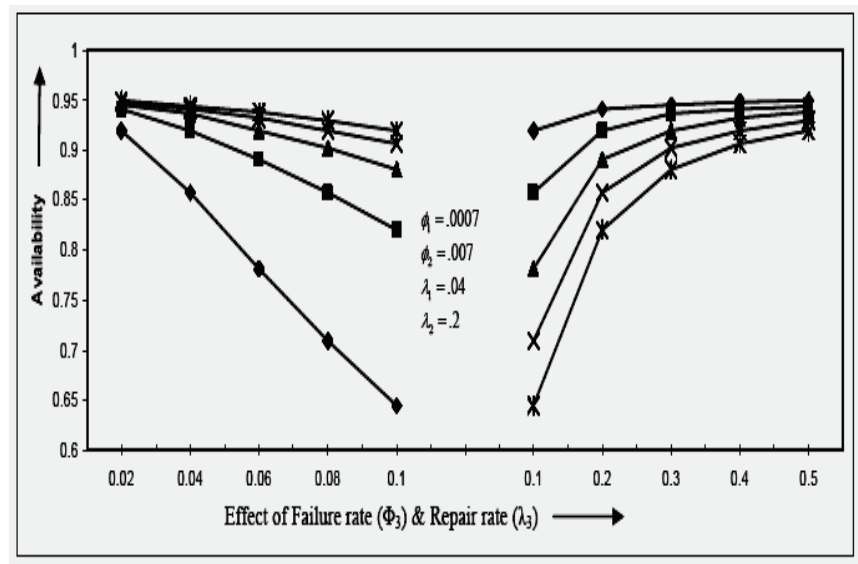

Figure 4: The effect of the failure and repair rate of the feed water pump subsystem on the feed water unit availability $\rightarrow$ Availability $(\mathrm{Av}) \rightarrow \mathrm{A}_{0}$ 


\begin{tabular}{|c|c|c|c|c|c|c|}
\hline $\begin{array}{l}\lambda_{3} \\
\phi_{3}\end{array}$ & .1 & .2 & .3 & .4 & .5 & $\begin{array}{c}\text { Constant } \\
\text { values }\end{array}$ \\
\hline .02 & .92 & .941 & .946 & .948 & .949 & $\phi_{1=.0007}$ \\
\hline .04 & .857 & .920 & .936 & .941 & .944 & $\phi_{2}=.007$ \\
\hline .06 & .782 & .891 & .920 & .932 & .938 & $\lambda_{1=.04}$ \\
\hline .08 & .710 & .857 & .902 & .920 & .930 & $\lambda_{2=.2}$ \\
\hline .1 & .644 & .820 & .880 & .907 & .920 & \\
\hline
\end{tabular}

Table 3: Decision matrix of the feed water pump sub system of the feed water unit

Table 3 and Figure 4 explain the effect of the failure and repair rates of the feed water pump subsystem on the availability of the feed water unit. It is observed that for some known values of failure / repair rates of boiler and condenser $\left(\phi_{2}=0.007\right.$, $\phi_{1}=0.0007, \lambda_{1}=0.04, \lambda_{2}=0.2$ ), as the failure rate of the feed water pump increases from 0.02 (once in $50 \mathrm{hrs}$ ) to 0.1 (once in $10 \mathrm{hrs}$ ), the unit availability decreases by approximately $30 \%$. Similarly, as the repair rate of the feed water pump increases from 0.10 (once in $10 \mathrm{hrs}$ ) to 0.50 (once in $2 \mathrm{hrs}$ ), the unit availability increases by approximately $3 \%$.

\section{CONCLUSIONS}

The decision support system for the feed water unit has been developed with the help of mathematical modeling using a probabilistic approach. The decision matrices are also developed. The matrices facilitate the maintenance decisions to be made at critical points where repair priority should be given to some particular subsystem of the feed water unit. The decision matrix given in Table 3 and Figure 4 clearly indicates that the feed water pump is the most critical subsystem as far as maintenance is concerned. So the feed water pump subsystem should be given top priority, as the effect of its failure and repair rates on the unit availability is much higher than that of the boiler and condenser subsystems. Therefore, on the basis of repair rates, the maintenance priority should be as follows:

\section{Feed water pump \\ 2. Condenser \\ 3. Boiler}

The main objective of the decision support system developed here is to decide on the relative maintenance priorities for the three subsystems (feed water pump, condenser, and boiler) of the feed water unit. The findings of this paper will greatly benefit the plant management as they decide about the correct and orderly execution of proper maintenance, and thus enhance the performance of the feed water unit of a thermal power plant. 


\section{REFERENCES}

[1] Jardine, A.K.S. 1998. Maintenance, replacement and reliability. Ontario, Canada: Preney Print and Litho Inc.

[2] O’Connor, P.D.T. 1991. Practical reliability engineering. $3^{\text {rd }}$ ed. England, Wiley.

[3] Billinton, R., Allan, R.N. 1983. Reliability evaluation of engineering systems: Concepts and techniques. Boston: Pitman Books Limited.

[4] Ross, S.M. 1970. Applied probability models with optimization applications. San Francisco: Holden Day.

[5] Kumar, S., Chattopadhyay, G., Kumar, U. 2007. Reliability improvement through alternative designs-A case study. Int. Journal of Reliability Engineering and System Safety, Vol. 92, pp. 983-991.

[6] Tewari, P.C., Kumar, D. 1992. Maintenance management of feed water system. Proceedings of All India Seminar on Pumping System Selection, Maintenance \& Management, Roorkee (India).

[7] Tewari, P.C., Sharma, A.K. 2004. Reliability modeling for feed water system circuit in thermal power plant. Energy \& Environment, Anamaya Publishers, New Delhi.

[8] Natvig, B., Jonson, N., Kotz, S. 1984. Multi-state coherent systems. Encyclopedia of Statistical Sciences, Vol. 5. New York: Wiley.

[9] Lisnianski, A. 2007. Extended block diagram method for a multi-state system reliability assessment. Reliability Engineering and System Safety, Vol.92, pp.1601-1607.

[10] Dhillon, B.S., Singh, C. 1981. Engineering reliability - New techniques and applications, John Wiley and Sons, NewYork.

[11] Srinath, L.S. 1994. Reliability engineering, $3^{\text {rd }}$ edition, East-West Press Pvt. Ltd., New Delhi.

[12] Kuo, W., Prasad, V.R., Tillman, F.A., Hwang, C.L. 2001. Optimal reliability design: Fundamentals and applications. Cambridge: Cambridge University Press.

[13] Yu, H., Chu, C., Châtelet, E., and Yalaoui, F. 2007. Reliability optimization of a redundant system with failure dependencies. Reliability Engineering and System Safety Vol. 92, pp. 1627-1634. 